\title{
Developmental Changes in Thickness, Contractility, and Hypoxic Sensitivity of Newborn Lamb Cerebral Arteries
}

\author{
WILLIAM J. PEARCE AND STEPHEN ASHWAL \\ The Macpherson Laboratory, White Memorial Medical Center, Los Angeles [W.J.P.]; Department of Physiology, \\ Loma Linda University School of Medicine, Loma Linda [W.J.P.J; and Department of Pediatrics, Loma Linda \\ University School of Medicine, Loma Linda, California [S.A.]
}

\begin{abstract}
The present studies were conducted to examine the possibility that the increased vulnerability of the newborn brain to hypoxia may be due to age-related differences in vascular thickness and contractility. Segments of rostral choroidal (RC), posterior communicating (PC), basilar (B), and common carotid (CC) arteries were taken from 3- to 7-day-old lambs $(n=11)$ and adult sheep $(n=8)$ and studied using standard in vitro techniques. In lamb cerebral arteries, maturation was associated with significant increases in vessel thickness and tension generation. Because the increases in tension generation $(77,90$, and $135 \%$ in PC, B, and RC segments) were proportionately greater than the corresponding increases in thickness $(45,75$, and $34 \%$ in $\mathrm{PC}, \mathrm{B}$, and $\mathrm{RC}$ ), force per unit area increased with maturation in the cerebral arteries. In the $\mathrm{CC}$ segments, the age-related increases in thickness $(117 \%)$ were greater than the increases in tension generation $(30 \%)$, such that average force per unit area was actually greater in the lamb than in the sheep. In response to hypoxia $\left(\mathrm{PO}_{2}<15\right.$ torr), all vessels exhibited significant relaxation relative to normoxic controls, although the rates and magnitudes of relaxation varied considerably. In the sheep, the carotid exhibited rapid relaxation of small magnitude $(21 \%)$, whereas the cerebral arteries relaxed more slowly and more completely $(56,52$, and $45 \%$ in $P C, B$, and $R C)$. In contrast, the lamb carotid segments relaxed more slowly than the cerebral arteries. Although the average magnitude of relaxation in the lamb carotids $\mathbf{( 4 0 \% )}$ was less than in the lamb cerebral vessels $(69,48$, and $79 \%$ in $P C, B$, and $R C)$, it was twice as great as that observed in the sheep carotids (21\%). These data indicate that the pattern of response to hypoxia was markedly different in the lamb and sheep and suggest that the carotid artery may play a more important role in the regulation of cerebrovascular resistance in the newborn than in the adult. This may be of clinical importance in the newborn in which variations in cerebral perfusion pressure occur during hypoxia. (Pediatr Res 22: 192-196, 1987)
\end{abstract}

Perinatal hypoxia and asphyxia are frequently associated with myocardial dysfunction, hypotension, and a variety of metabolic changes including acidosis and catecholamine release. In the brain these insults often precipitate the development of cerebral

Received November 20, 1985; accepted March 11, 1987.

Correspondence William Pearce, Ph.D., Macpherson Laboratory, White Memorial Medical Center, 1720 Brooklyn Avenue, Los Angeles, CA 90033.

Supported by American Heart Association Grant 784-G1-2, White Memorial Medical Center, and Pediatric Research Fund, Loma Linda. ischemia, edema, and infarction. Concomitant elevations in arterial carbon dioxide tension and compensatory increases in blood pressure may acutely increase cerebral blood flow, but these changes can also contribute to the development of subependymal or intraventricular hemorrhage $(1,2)$, particularly upon reoxygenation. Such pathophysiological changes demonstrate that regulation of cerebral perfusion in the newborn is impaired by hypoxia (3). The reasons for this impairment, however, remain unclear.

The vulnerability of the newborn cerebral circulation to hypoxic damage may be due to age-related differences in vascular structure and function. In newborn vessels, wall thickness and tension-generating capacity are decreased relative to corresponding adult vessels (4). Adrenergic innervation and receptor sensitivity are also decreased $(5,6)$. These differences are of importance not only at the microcirculatory level, but also in the large cerebral arteries which, in the adult, can contribute up to $50 \%$ of total cerebrovascular resistance (7). Thus, newborn vessels may not be able to adjust with the speed and force required to maintain cerebral perfusion during hypoxia, or to limit cerebral perfusion during reoxygenation. To explore this hypothesis, we examined the rates and magnitudes of relaxation during hypoxia in carotid and cerebral arteries isolated from newborn lambs and adult sheep. Vessel thicknesses and normoxic force development were also examined and compared. We paid particular attention to the differences between carotid and cerebral arteries, and to the effects of maturation on these differences.

\section{METHODS}

Segments of rostral choroidal, posterior communicating, basilar, and common carotid arteries were obtained from 3- to 7day-old lambs and adult sheep and studied using standard in vitro techniques $(5,8)$. Each segment was cut to a length of 5 $\mathrm{mm}$, cannulated with mounting wires, and suspended between a Grass FT. 03 force transducer and a post attached to a micrometer used to control resting tension. The segments were equilibrated in a bicarbonate Krebs solution containing (in $\mathrm{mM} /$ liter): $\mathrm{NaCl}$ $122, \mathrm{NaHCO}_{3} 25.6$, dextrose 5.56, $\mathrm{KCl} 5.17, \mathrm{MgSO}_{4} 2.49, \mathrm{CaCl}_{2}$ 1.60, ascorbic acid 0.114, and disodium EDTA 0.027. During equilibration, the vessel segments were stretched to obtain optimal resting tensions of 0.5 to $1.0 \mathrm{~g}$ for the cerebral and carotid artery segments. Optimal values of resting tension were determined in preliminary length-tension studies. Unless otherwise specified, the vessels were continuously bubbled with $95 \% \mathrm{O}_{2}$, $5 \% \mathrm{CO}_{2}$ and maintained at normal body temperature.

Each vessel segment was contracted three times in succession by exposure to an isotonic Krebs solution containing $120 \mathrm{mM}$ $\mathrm{KCl}$ and $5.2 \mathrm{mM} \mathrm{NaCl}$. Each contraction lasted $24 \mathrm{~min}$, with a 30 -min rest period in normal Krebs allowed between consecutive 
contractions. In normoxia (control) experiments, $95 \% \mathrm{O}_{2}$ with $5 \% \mathrm{CO}_{2}$ was bubbled through the baths during all contractions. In hypoxia experiments, $95 \% \mathrm{~N}_{2}$ with $5 \% \mathrm{CO}_{2}$ was bubbled through the baths during contraction 3 . As measured with an oxygen electrode, bath oxygen tension dropped to less than 15
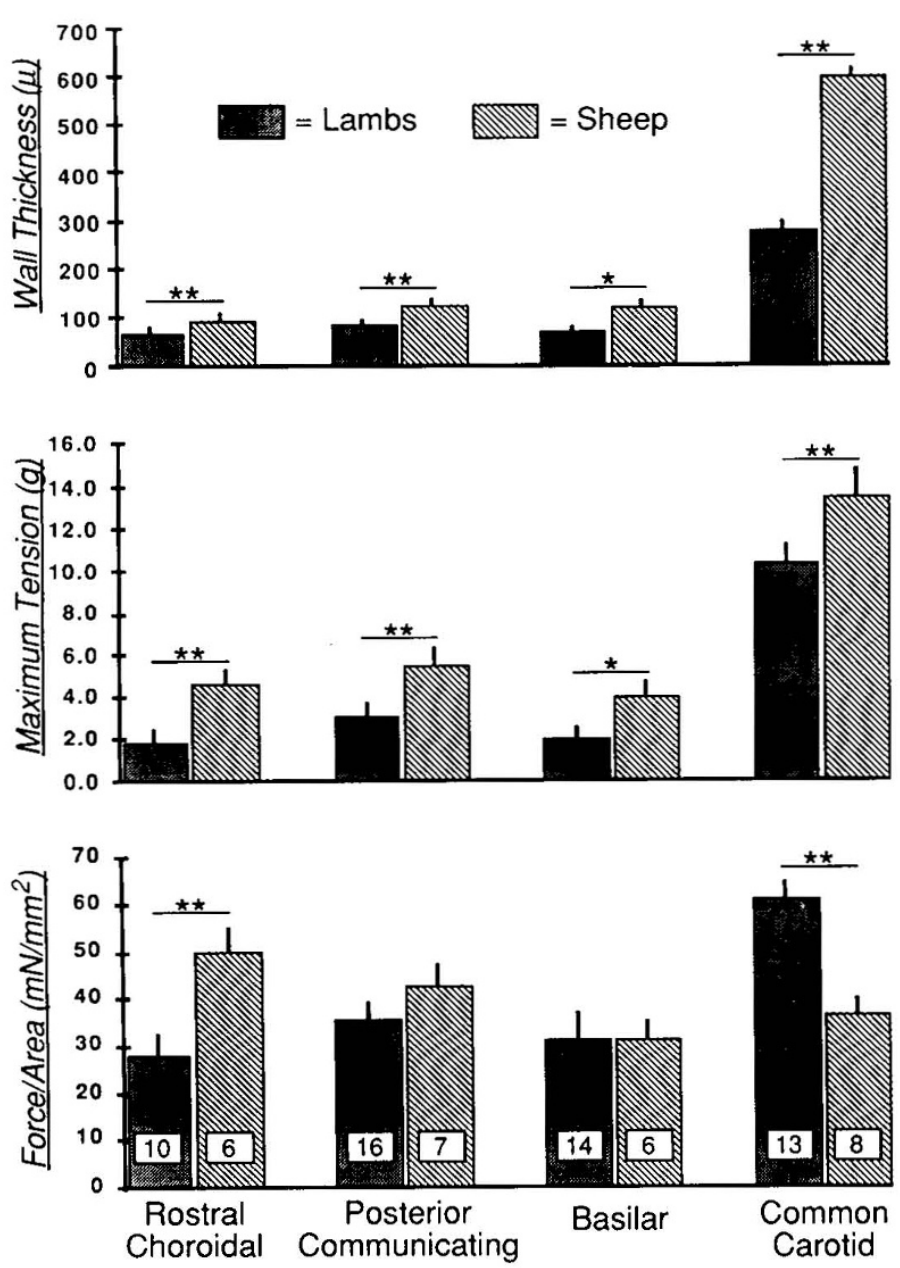

Fig. 1. Vessel thickness, tension generation, and force per unit crosssectional area in lamb and sheep arteries. Means and SEs are given for vessel thickness, maximum tension, and force per unit area in the upper, middle, and lower panels, respectively. The number of vessels in each group is given in the open rectangles in the lower panel. The probability values of significant differences between corresponding lamb and sheep vessels are also indicated $\left(*, p<0.05,{ }^{* *}, p<0.01\right)$. torr within 3 min of bubbling with the $\mathrm{N}_{2}-\mathrm{CO}_{2}$ mixture. A total of 16 experimental groups was employed: a normoxia (control) group and a hypoxia group for each of the four vessels studied in both the lamb and the sheep. During each experiment, contractile tensions were recorded, digitized, and normalized by online computer (9).

The magnitude of hypoxic relaxation was calculated for each vessel as the percent difference between initial normoxic tension and the tension remaining after $20 \mathrm{~min}$ of hypoxia. The rate of relaxation to hypoxia was calculated by fitting the normalized experimental data to the equation:

$$
y=(A-B) * e^{-k t}+B
$$

where $y=$ the $\%$ maximum normalized tension remaining at time $\mathrm{t}, \mathrm{A}=$ the $\%$ maximum normalized tension at time zero (approximately $100 \%$ ), $\mathrm{k}=$ the exponential rate constant of relaxation, and $\mathrm{B}$ is the \% maximum tension at steady state. $\mathrm{A}$ computerized reiterative minimization routine was used to obtain five significant digits each for $\mathrm{A}, \mathrm{B}$, and $\mathrm{k}$. The average SEs of fit obtained with this program ranged from 0.08 to $1.33 \%$.

Wall thickness was measured in a representative section of each segment selected for contractility studies. Each wall thickness segment was immersed in $2 \%$ lidocaine, opened along its longitudinal axis, placed on a microscope slide, and covered with coverglass. Wall thickness was then determined optically by measuring the vertical distance between the slide and the coverglass, as previously described (8). The thickness recorded for each vessel segment was the mean of 10 measurements. Cross-sectional area was calculated as two times the product of segment thickness and length, and was divided into maximum force to calculate force per unit area (10). Maximum force was calculated as the product of maximum tension and the acceleration due to gravity. Maximum tension was defined as the peak normoxic tension produced by each vessel during the first exposure to the high potassium Krebs solution.

Group means for each variable were compared using a 2-way analysis of variance with a Duncan's multiple range test (11). A total of five variables was analyzed in this manner, including vessel thickness, maximum tension, force per unit cross-sectional area, magnitude of relaxation, and relaxation rate.

\section{RESULTS}

In lamb cerebral arteries, vessel thicknesses and maximum tensions were significantly less than in corresponding adult vessels (Fig. 1 and Table 1). On a percentage basis, the age-related increase in thickness was greatest in the basilar $(75 \%)$ and least in the rostral choroidal (34\%). In contrast, the age-related increase in maximum tension was greatest in the rostral choroidal $(135 \%)$ and least in the posterior communicating (77\%). The

Table 1. Values for vessel thickness, maximum tension, force per unit area, rate, and magnitude of relaxation to hypoxia*

\begin{tabular}{cccccc}
\hline Vessel & Thickness $(\mu)$ & $\begin{array}{c}\text { Maximum } \\
\text { tension }(\mathrm{g})\end{array}$ & $\begin{array}{c}\text { Force/unit area } \\
\left(\mathrm{mN} / \mathrm{mm}^{2}\right)\end{array}$ & Rate $\left(10^{-4} / \mathrm{s}\right)$ & $\begin{array}{c}\text { Magnitude } \\
(\% \text { decrease })\end{array}$ \\
\hline LAMB & & & & & \\
R Chor & $71 \pm 4(10)$ & $2.0 \pm 0.2(10)$ & $28.5 \pm 4.2(10)$ & $42.4 \pm 4.5(8)$ & $78.7 \pm 1.9(8)$ \\
P Comm & $87 \pm 3(16)$ & $3.1 \pm 0.3(16)$ & $35.9 \pm 3.5(16)$ & $32.2 \pm 4.4(11)$ & $68.9 \pm 4.9(11)$ \\
Basilar & $71 \pm 5(14)$ & $2.1 \pm 0.2(14)$ & $31.4 \pm 5.4(14)$ & $39.4 \pm 6.8(8)$ & $47.6 \pm 5.8(8)$ \\
Carotid & $281 \pm 8(13)$ & $10.4 \pm 0.5(13)$ & $61.2 \pm 3.4(13)$ & $13.9 \pm 3.3(11)$ & $39.9 \pm 3.1(11)$ \\
Sheep & & & & & \\
R Chor & $95 \pm 9(6)$ & $4.7 \pm 0.3(6)$ & $50.5 \pm 4.6(6)$ & $17.1 \pm 3.8(6)$ & $44.6 \pm 4.2(6)$ \\
P Comm & $126 \pm 6(7)$ & $5.5 \pm 0.6(7)$ & $42.8 \pm 4.3(7)$ & $19.7 \pm 2.5(8)$ & $55.6 \pm 3.3(8)$ \\
Basilar & $124 \pm 7(6)$ & $4.0 \pm 0.5(6)$ & $31.7 \pm 3.7(6)$ & $22.8 \pm 2.8(6)$ & $52.4 \pm 3.1(6)$ \\
Carotid & $609 \pm 11(8)$ & $13.5 \pm 1.0(8)$ & $36.8 \pm 3.0(8)$ & $61.9 \pm 6.3(6)$ & $20.5 \pm 2.2(6)$ \\
\hline
\end{tabular}

* Abbreviations: R Chor, rostral choroidal; P Comm, posterior communicating. All values are given as the mean \pm SE with the number of observations given in parentheses. The values of thickness, maximum tension, and force/unit area are depicted in Figure 1. The rates and magnitudes of hypoxic relaxation are illustrated in Figure 4. 
combined effects of these differences are reflected in the force/ unit area data which indicate that force generation develops at different rates in different vessels, and that the effects of maturation on force generation were greater for the more peripheral rostral choroidal artery, than for the more central posterior communicating and basilar arteries.

In the carotid artery segments, thickness and maximum tension were significantly less in the lamb than in the sheep. Maturation was associated with more than a 2 -fold increase in thickness, but only a $30 \%$ increase in maximum tension. Thus, maximum force per unit area appears to decrease significantly with age in the common carotid artery.

In response to hypoxia, all vessels exhibited significant relaxation relative to normoxic controls (Figs. 2 and 3). The rates and magnitudes of these responses, however, varied considerably (Table 1 and Fig. 4). In the cerebral arteries, maturation was associated with decreases in both the rates and magnitudes of response to hypoxia. On a percentage basis, the age-related decreases in rate and magnitude were both greatest in the rostral choroidal artery (60 and $22 \%$, respectively). In the common carotid artery, however, development was associated with more than a 4-fold increase in the rate and a $49 \%$ decrease in the magnitude of relaxation. Thus, sensitivity to hypoxia changes dramatically with development, and the extent of these changes vary considerably between intracranial and extracranial arteries.

\section{DISCUSSION}

One of the key features of the present data is the marked difference in the effects of development on carotid and cerebral

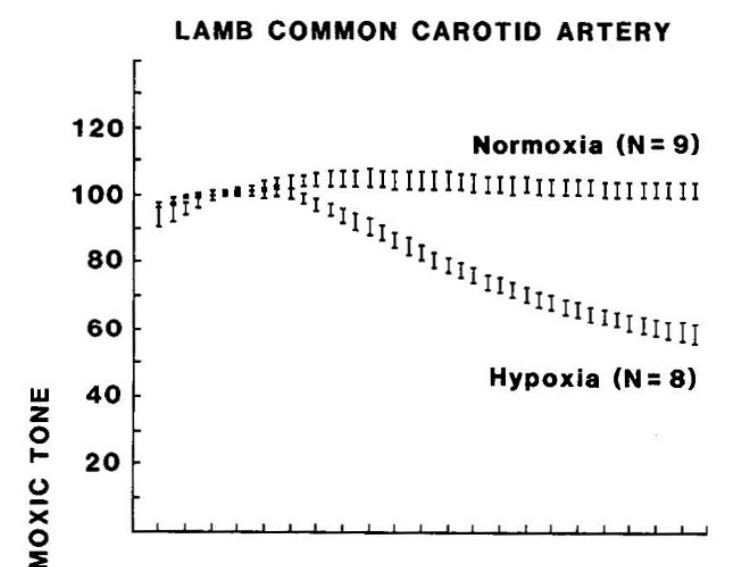

LAMB ROSTRAL CHOROIDAL ARTERY

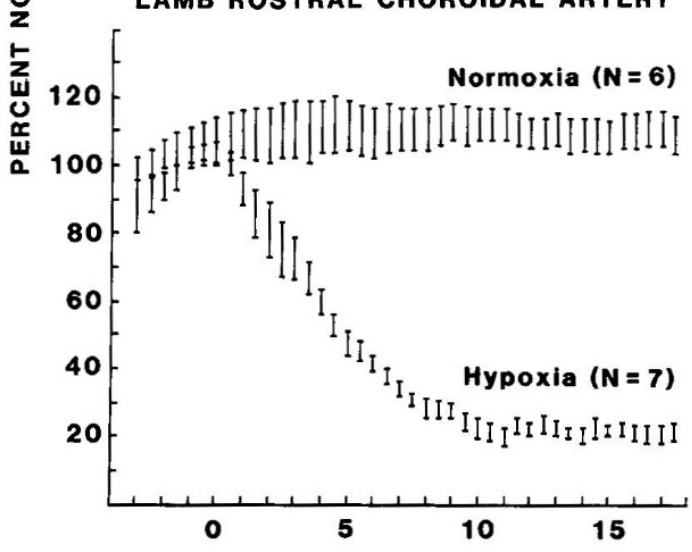

arteries. In the carotid, age-related increases in wall thickness far exceeded the increases in tension-generating capacity, such that force per unit area actually decreased significantly. This pattern suggests that the postnatal hypertrophy of the carotid wall is due more to increases in collagen and elastin than to increases in the content of contractile proteins $(4,12)$. In contrast, development of the cerebral arteries was associated with proportionately smaller increases in wall thickness and greater increases in maximum tension than observed in the carotid. Thus, force per unit area either increased or did not change, suggesting that during maturation of cerebral arteries, synthesis of new collagen and elastin is not as important as development of the contractile apparatus. Although the present data do not enable differentiation between the mechanisms mediating this improvement in contractile capacity, other studies suggest that age-related increases in actomyosin content and calcium-binding capacity may be involved $(13,14)$.

Heterogeneity in the effects of development was also evident in the responses of the isolated arteries to hypoxia. With development, both rate and magnitude of relaxation decreased in the cerebral arteries, with the greatest age-related decreases in the rostral choroidal arteries. Maturation of the common carotid was associated with a decrease in magnitude, but also with a marked increase in the rate of response to hypoxia. Thus, the patterns of response to hypoxia were markedly different in the lamb and sheep. In the sheep, the carotid responded quickly but to a small extent suggesting that in the intact animal, the main adjustments to hypoxia may be made more slowly by the cerebral arteries. In the lamb, however, the cerebral vessels relaxed more quickly and completely than the carotid.

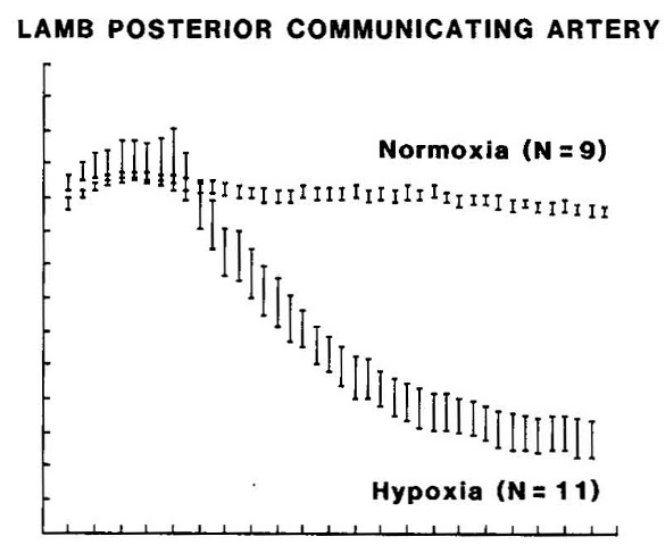

LAMB BASILAR ARTERY

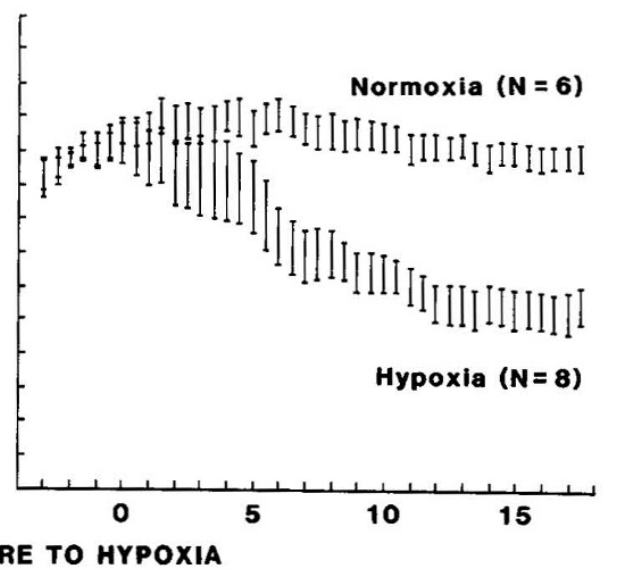

Fig. 2. Hypoxic relaxation of potassium-induced tone in isolated lamb arteries. Each of the indicated vessels were contracted with an isotonic Krebs solution containing $120 \mathrm{mM} \mathrm{KCl}$, allowed to equilibrate for $4 \mathrm{~min}$, then exposed to hypoxia $\left(\mathrm{PO}_{2}<15\right.$ torr) for 20 min. The vertical bars represent normalized tension (mean $\pm \mathrm{SE}$ ) for the indicated number of vessels. All decreases in tension produced by hypoxia were significant $(p<$ $0.01)$. 


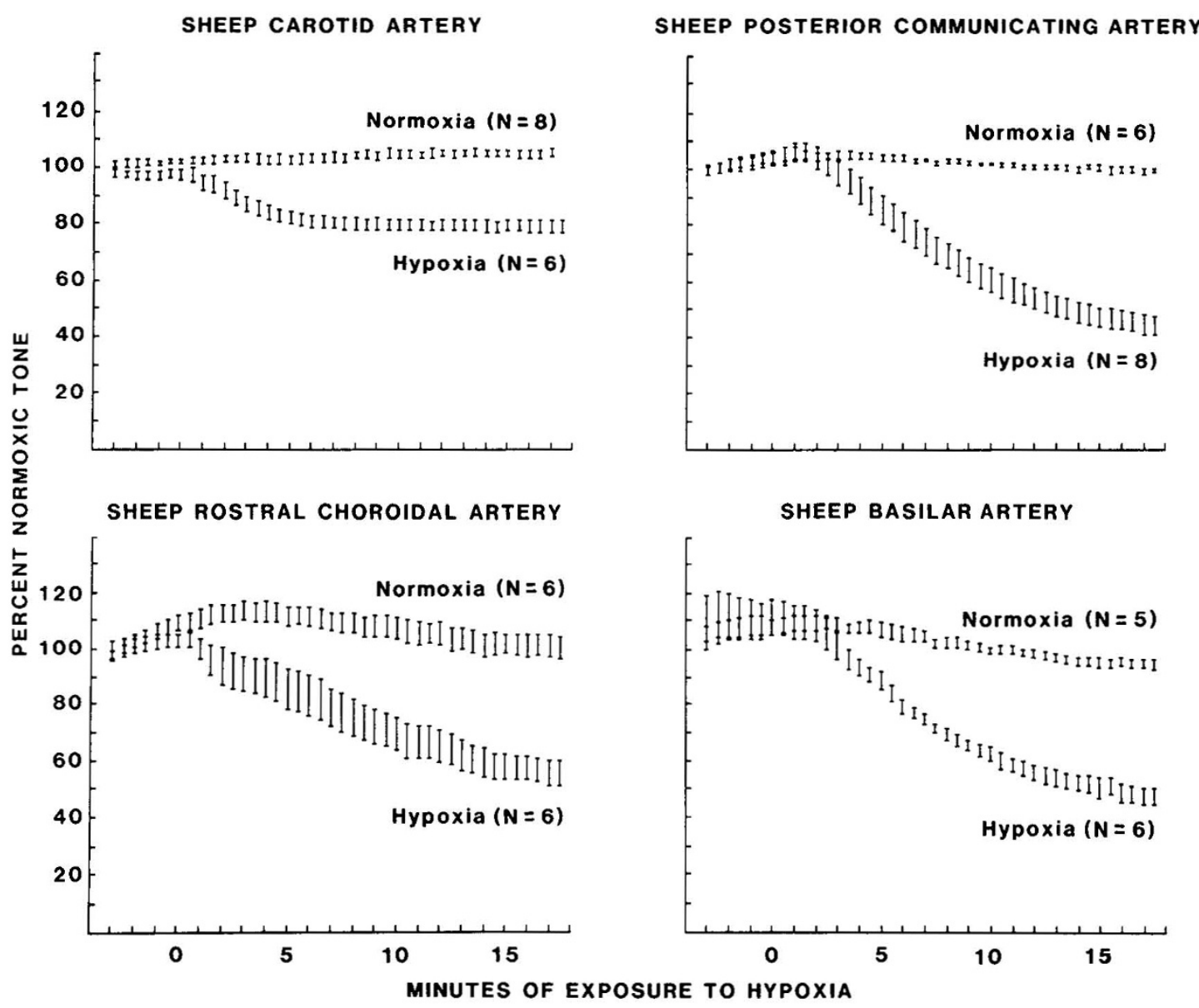

Fig. 3. Hypoxic relaxation of potassium-induced tone in isolated sheep arteries. The data shown herein were collected and plotted as described in Figure 2. In all sheep vessels, the decreases in tension produced by 20 min of hypoxia $\left(\mathrm{PO}_{2}<15\right.$ torr) were significant at $p<0.01$.

The reasons for the observed age-related differences in response to hypoxia remain unclear. Although vessel thickness has been cited as a major determinant of the magnitude of relaxation (15), other factors clearly must be involved because the magnitudes of relaxation decreased in the common carotid, posterior communicating, and rostral choroidal arteries while vessel thicknesses were increasing with age. Because all responses to hypoxia were obtained under conditions of complete membrane depolarization, it is doubtful that differences in the effects of hypoxia on membrane hyperpolarization $(16,17)$ could have contributed to the observed age-related differences in response to hypoxia. Similarly, it is doubtful that hypoxia-induced changes in sodiumcalcium exchange (18) were involved since extracellular sodium concentration during hypoxia was too low to support this mechanism (19). It remains possible, however, that other factors suggested to play a role in hypoxic relaxation, such as release of a relaxing factor from the vascular endothelium (20), inhibition of calcium uptake $(21,22)$, stimulation of calcium extrusion $(23$, $24)$, or changes in anaerobic glycolytic capacity $(25,26)$ may be involved in the changing sensitivity to hypoxia which occurs with age. Future experiments will be required to determine the relative role of each of these mechanisms.

Although the present data do not distinguish between the factors potentially responsible for the age-related differences in hypoxic sensitivity, the data do point to factors which may have bearing on the increased incidence of intracranial hemorrhage in post asphyxic newborns $(1,2)$. In the adult, force per unit area appears to increase as one moves toward the periphery (basilar $<$ posterior communicating $<$ rostral choroidal) and the magnitude of relaxation is relatively uniform across the cerebral arteries
( 45 to $56 \%$ ). In the lamb, however, force per unit area is smallest in the rostral choroidal artery and the magnitude of relaxation appears to increase as one moves toward the periphery (rostral choroidal $>$ posterior communicating $>$ basilar $>$ carotid). Thus, it appears that relative to the carotid arteries, the peripheral vessels of the cerebral circulation are more poorly developed in the lamb than in the sheep. This suggests that the contribution of the carotid to cerebrovascular resistance, which has been reported to be 30 to $50 \%$ of total cerebrovascular resistance in adults (7), may be much greater in the lamb than in the sheep. Such an age-related difference could be critically important during hypoxia, particularly in the event of a precipitous rise in cerebral perfusion pressure. Because the present data suggest that the carotid dilates more in the lamb than in the sheep during hypoxia, increased cerebral perfusion pressure in the lamb might more easily be communicated to the dilated peripheral vessels and precipitate rupture. Given that the lamb carotid relaxes more slowly to hypoxia than does the sheep carotid, it may also constrict more slowly in response to rises in perfusion pressure during hypoxia, particularly since the adrenergic innervation of the carotid is less developed in the lamb than in the sheep. Consistent with this idea, other situations associated with rapid rises in arterial pressure are also associated with an increased incidence of intracranial hemorrhage in the newborn (27).

In conclusion, the present studies indicate that the maturation of cerebral arteries is associated with significant increases in thickness, tension generation, and force per unit area, in addition to decreases in the rate and magnitude of relaxation to hypoxia. Development of the carotid arteries is associated with increases in thickness, tension generation, and rate of response to hypoxia, 


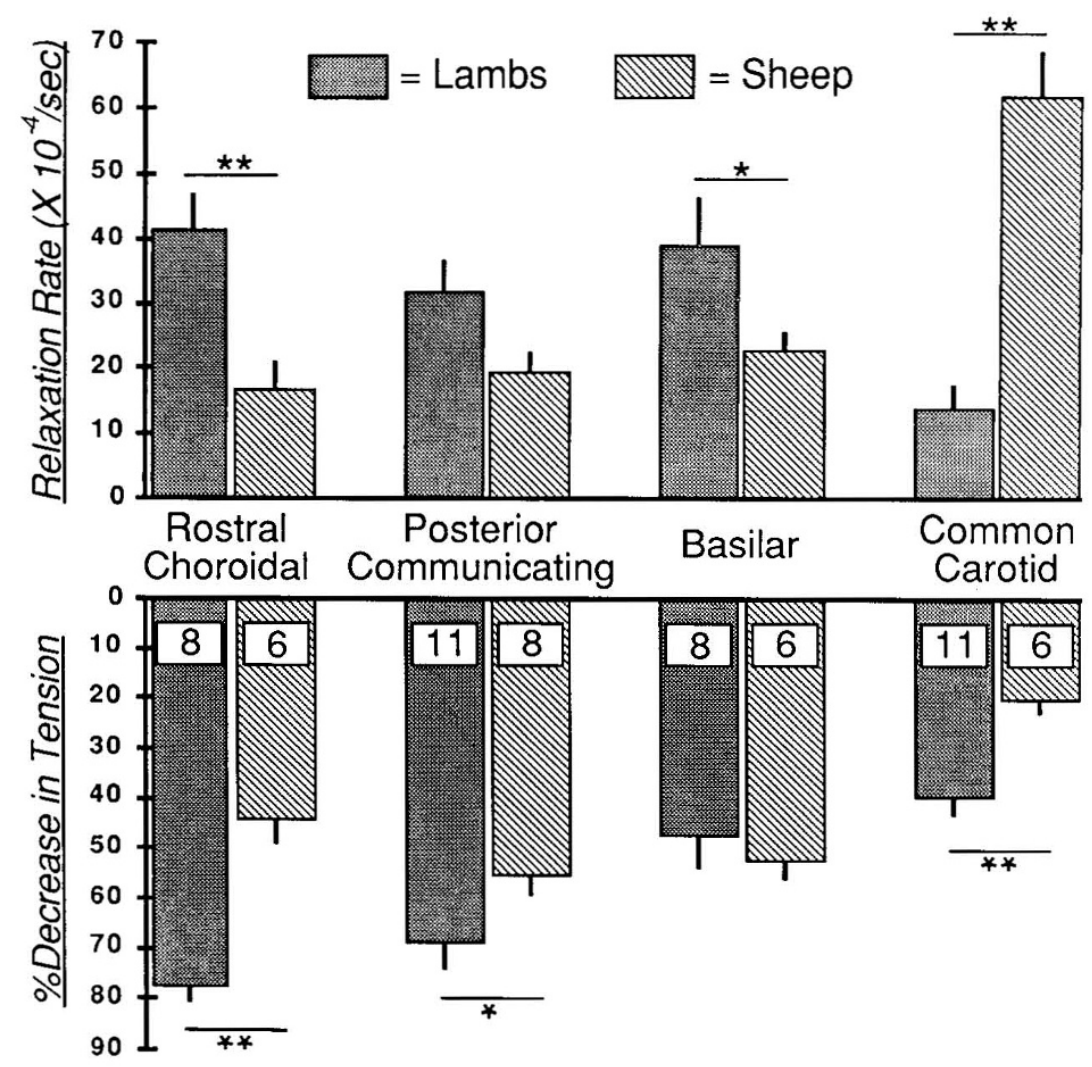

Fig. 4. Rate and magnitude of hypoxic relaxation in lamb and sheep arteries. The average rates of response to hypoxia are plotted in the upper panel. In the lower panel, the average magnitudes of relaxation are indicated as percent decrease from normoxic control. The vertical bars represent SEs and the number of vessels in each group is given in the open rectangles in the lower panel. The probability values of significant differences between corresponding lamb and sheep vessels are also indicated $\left(^{*}, p<0.05,{ }^{* *}, p<0.01\right)$. For reference, a rate of $50 \times 10^{-4} / \mathrm{s}$ corresponds to a time constant of approximately $3.3 \mathrm{~min}$.

and with decreases in force per unit area and the magnitude of relaxation to hypoxia. We interpret these age-related changes to indicate that the patterns of response to hypoxia are markedly different in the newborn and adult. In the newborn, the cerebral arteries relax more quickly and completely and thus, the slower reacting carotid appears to play a more important regulatory role than in the adult. These differences, we believe, may contribute to the increased incidence of intracranial hemorrhage observed in hypoxic infants.

\section{REFERENCES}

1. Volpe JJ 1981 Hypoxic-Ischemic brain injury and intracranial hemorrhage. In: Volpe JJ (ed) Neurology of the Newborn. WB Saunders Company, Philadelphia, pp 141-298

2. McPhee AJ, Kotagal UR, Kleinman LI 1985 Cerebrovascular hemodynamics during and after recovery from acute asphysia in the newborn dog. Pediatr Res 19:645-650

3. Tweed A, Cote J, Lou H, Gregory G, Wade J 1986 Impairment of cerebral blood flow autoregulation in the newborn lamb by hypoxia. Pediatr Res 20:516-519

4. Duckles SP, Banner W 1984 Changes in vascular smooth muscle reactivity during development. Ann Rev Pharmacol Toxicol 24:65-83

5. Su C, Bevan JA, Assali NS, Brinkman CR 1977 Regional variation of lamb blood vessel responsiveness to vasoactive agents during fetal development. Circ Res 41:844-848

6. Wyse DG, Van Patten GR, Harris WH 1977 Responses to electrical stimulation, noradrenalin, serotonin and vasopressin in the isolated ear artery of the developing lamb and ewe. Can J Physiol Pharmacol 55:1001-1006

7. Baumbaugh GL, Heistad DD 1985 Regional, segmental, and temporal heterogeneity of cerebral vascular autoregulation. Ann Biomed Eng 13:303-310

8. Pearce WJ, Bevan JA 1984 Retroglenoid venoconstriction and its influence on canine intracranial venous pressures. J Cereb Blood Flow Metab 4:373-380

9. Pearce WJ, Ashwal S, Longo LD 1985 The role of membrane hyperpolarization in the direct effects of hypoxia on isolated cerebral arteries. Proc West Pharmacol Soc 28:131-134

10. Murphy RA 1980 Mechanics of vascular smooth muscle. In: Sheperd JT, Abboud FM (eds) Handbook of Physiology, section 2, vol III. American Physiological Society, Bethesda, pp 325-351
11. Duncan DB 1955 Multiple range and multiple F tests. Biometrics 11:1-42

12. Cox RH, Jones AW, Fischer GM 1974 Carotid artery mechanics, connective tissue and electrolyte changes in puppies. Am J Physiol 227:563-568

13. Williams $P 1984$ Effect of age upon uptake and binding of calcium in rat aorta. Biochem Pharmacol 33:3097-3099

14. Seidel CL, Ross B, Michael L, Freedman J, Berdick B, Miller T 1987 Maturation changes in the pharmacological characteristics and actomyosin content of canine arterial and venous tissue. Pediatr Res 21:152-158

15. Pittman RN, Duling BR 1973 Oxygen sensitivity of vascular smooth muscle. Microvasc Res 6:202-211

16. Detar R, Bohr DF 1968 Oxygen and vascular smooth muscle contraction. Am J Physiol 214:241-244

17. Chang AE, Detar R 1980 Oxygen and vascular smooth muscle revisited. Am J Physiol 238:H716-728

18. Detar R 1980 Mechanism of physiological hypoxia-induced depression of vascular smooth muscle contraction. Am J Physiol 238:H761-H769

19. Petersen TT, Mulvany MJ 1984 Effect of sodium gradient on the rate of relaxation of rat mesenteric small arteries from potassium contractures. Blood Vessels 21:279-289

20. Busse R, Pohl U, Kellner C, Klemm U 1983 Endothelial cells are involved in the vasodilatory response to hypoxia. Pflugers Arch 397:78-80

21. Simeone FA, Vinall PE Pickard JD 1980 Response of extraparenchymal cerebral arteries to biochemical environment of cerebrospinal fluid. In: Wood JH (ed) Neurobiology of Cerebrospinal Fluid, vol 1. Plenum, New York, pp 303-311

22. Ebeigbe $A B 1982$ Influence of hypoxia on contractility and calcium uptake in rabbit aorta. Experientia 38:935-937

23. Pettersson G 1984 Influence of anoxia and dinitrophenol on $\mathrm{Ca}^{2+}$ efflux and phosphorylase a activity in rabbit colon smooth muscle. Acta Pharmacol Toxicol 54:15-21

24. Pearce WJ 1986 Mechanisms of hypoxic relaxation in isolated cerebral arteries: the effects of extracellular calcium concentration. Proc West Pharmacol Soc 29:199-202

25. Namm DH, Zucker JL 1973 Biochemical alterations caused by hypoxia in the isolated rabbit aorta. Correlation with changes in arterial contractility. Circ Res 32:464-470

26. Karaki H, Suzuki T, Ozaki H, Urakawa N, Ishida Y 1982 Dissociation of K+induced tension and cellular $\mathrm{Ca}^{2+}$ retention in vascular and intestinal smooth muscle in normoxia and hypoxia. Pflugers Arch 394:118-123

27. Batton DG, Hellmann J, Nardis EE 1984 Effect of pneumothorax-induced systemic blood pressure alterations on the cerebral circulation in newborn dogs. Pediatrics 74:350-353 